\title{
Colonización campesina, identidad y acuerdos comunitarios: la Línea Amarilla como experiencia de protección del bosque ${ }^{*}$
}

Peasant Colonization, Identity and Community Agreements: The Yellow Line as an Experience of Forest Protection

Colonização camponesa, identidade e acordos comunitários: a Linha Amarela como experiência de proteção do bosque

Claudia Quijano Mejía** Daniel Alfonso León ${ }^{* \star *}$

Recibido: 1 de febrero de 2019

Aprobado: 10 de octubre de 2019

Doi: https://www.doi.org/10.12804/revistas.urosario.edu.co/territorios/a.7650

Para citar este artículo:

Quijano Mejía, C., \& Alfonso León, D. (2020). Colonización campesina, identidad y acuerdos comunitarios: la Línea Amarilla como experiencia de protección del bosque. Territorios, (42-Especial), 1-23. https://www. doi.org/10.12804/revistas.urosario.edu.co/territorios/a.7650

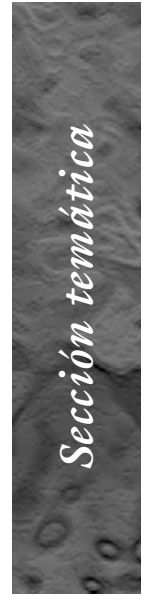

* Este artículo es un producto parcial del proyecto de investigación: Reconstrucción histórica de la ACVC desde un enfoque de género, financiado por Colciencias mediante la convocatoria 745 y ejecutado por el Grupo de Investigación Población Ambiente y Desarrollo de la Universidad Industrial de Santander, GPAD-UIS.

* Docente de la Universidad Industrial de Santander (Colombia). Correo electrónico: cmquijam@uis.edu.co ORCID: https://orcid. org/0000-0002-0224-5621

*** Integrante del Grupo de Investigación Población Ambiente y Desarrollo (GPAD-UIS) (Colombia). Correo electrónico: danieleon-@outlook.com ORCID: https://orcid. org/0000-0003-3940-4523 
Palabras clave

Identidad campesina, colonización campesina, Zona de Reserva

Campesina, memoria bistórica, acuerdos comunitarios.

Keywords

Peasant identity, peasant colonization, Peasant

Reserve Zone, historical memory, community agreements.

Palavras-chave

Identidade camponesa, colonização camponesa, Zona de Reserva Camponesa, memória histórica, acordos comunitários.

\section{territarias 42-Especial}

\section{RESUMEN}

El centro de discusión de este artículo es el proceso de construcción y movilización de la identidad campesina en el valle del río Cimitarra a través de la creación de iniciativas comunitarias de protección del medio ambiente, en específico, la denominada Línea Amarilla, una vasta franja de bosque primario al sur de la serranía de San Lucas, protegida por los campesinos mediante el establecimiento de acuerdos comunitarios de prohibición de actividades productivas o extractivas dentro de la zona. Se trata de un estudio cualitativo con enfoque de memoria histórica, que recurre a la voz de los protagonistas: campesinos colonos, impulsores de la iniciativa. El artículo discute cómo a través de las experiencias compartidas durante el proceso de colonización de la región y el establecimiento de acuerdos comunitarios se construye y recrea un "nosotros" que permite la interlocución con entidades y autoridades a nivel local y nacional.

\section{ABSTRACT}

The focus of discussion in this article is the process of construction and mobilization of the peasant identity in the valley of the Cimitarra river through the creation of community initiatives to protect the environment, specifically, the so-called Yellow Line: a vast stripe of primary forest south to the San Lucas mountain range, protected by peasants through the establishment of community agreements that prohibit productive or extractive activities within the area. The study is qualitative, with a focus on historical memory, based on the voice of the protagonists: peasant settlers who promote the initiative. The article discusses how, through the experiences shared during the process of colonization of the region and the establishment of community agreements, a self is created and recreated that allows the dialogue with local and national entities and authorities.

\section{RESUMO}

O centro de discussão deste artigo é o processo de construção e mobilização da identidade camponesa no vale do rio Cimitarra através da criação de iniciativas comunitárias de proteção ao meio ambiente, especificamente, a denominada Linha Amarela, uma vasta faixa de bosque primário ao sul da serrania de San Lucas, protegida pelos camponeses mediante o estabelecimento de acordos comunitários de proibição de atividades produtivas e/ou extrativas ao interior da zona. É um estudo de carácter qualitativo, com enfoque de memória histórica, que recorre à voz dos protagonistas: camponeses colonos impulsores da iniciativa. $\mathrm{O}$ artigo discute como através das experiências compartilhadas durante o processo de colonização da região e o estabelecimento de acordos comunitários se constrói e recreia um nós que permite a interlocução com entidades e autoridades no nível local e nacional. 


\section{Introducción}

En Colombia, las comunidades rurales que han enfrentado directamente el conflicto armado, en su mayoría, están localizadas en zonas de reciente colonización y son producto de las migraciones internas generadas por la misma guerra y la búsqueda de mejores condiciones económicas que ofrecen principalmente los cultivos ilícitos, la minería y la extracción de madera. Sin embargo, la ocupación de estas zonas son experiencias que están distantes de ser simplemente un proceso de uso irracional de los recursos naturales, que merecen una mirada atenta que las comprenda en su complejidad.

En el Magdalena Medio, es posible destacar el caso de la Asociación Campesina del valle del río Cimitarra (ACVC), organización comunitaria que ha sido reconocida por la resistencia, que ha emprendido en sus más de 20 años de existencia una labor contra el desplazamiento forzado y la guerra, a favor de la autonomía y el territorio campesino (Silva Prada, 2012). Esta organización ha adelantado diversas iniciativas que buscan la protección de los recursos naturales, entre ellas destacamos la iniciativa: Línea Amarilla, como es conocida por los campesinos. La Línea Amarilla es un proceso de establecimiento de un límite a la colonización que los campesinos/as demarcaron. Es un territorio en el que no es permitida la caza, la extracción de madera o el establecimiento de fincas, y hace parte de los acuerdos comunitarios de la región. Hoy se estima que la iniciativa abarca cerca de 70000 hectáreas de bosque nativo (ACVC, 2017), reconocida incluso por el gobierno nacional mediante la puesta en marcha del programa Bosques de Paz en la vereda Puerto Matilde (Yondó, Antioquia) y la alianza establecida entre la ACVC y Parques Nacionales Naturales (PNN) en la búsqueda de figuras de protección ambiental en la zona. Esto evidencia la importancia de las comunidades locales en la búsqueda de soluciones a la crisis ambiental actual, dentro de lo que Elinor Ostrom (2000) llama el gobierno de los bienes comunes o lo que Enrique Leff $(2009 ; 2004 b)$ - desde otra postura teórico-conceptual-denomina el paradigma de la racionalidad ambiental, en contraposición a la de la racionalidad económica imperante en el mundo hoy y causante de la crisis ambiental actual.

Esta racionalidad ambiental consta de tres niveles articulados e interdependientes: el primero, el nivel cultural, referente a los conocimientos de las comunidades sobre su entorno, así como sus formas organizativas, su identidad, sus prácticas tradicionales de uso y gestión de los recursos naturales; el segundo, el ecológico, relativo a la conservación de la fertilidad de los suelos y la manutención de las estructuras funcionales de los ecosistemas, que genera condiciones de estabilidad y renovación de los recursos naturales, y el tercero, el tecnológico, que no debe ser evaluado tan solo por su eficiencia y productividad, territarios 42-Especial 
sino principalmente por sus efectos en el nivel ecológico y cultural. En ese sentido, la preservación de las identidades campesinas e indígenas y, con ello, sus valores tradicionales, sus prácticas y la relación que han construido con la tierra y el territorio son soportes para la conservación de la biodiversidad, del equilibrio, la resiliencia y la complejidad del ecosistema (Leff, 2009).

Para el caso de estudio, más allá de las discusiones sobre la existencia o no del campesino y de la complejidad que acarrea la categoría, se considera pertinente su uso en la medida que existen personas y organizaciones que se identifican como tal y reivindican para sí dicha categoría ( $\mathrm{Ma}-$ tijasevic, 2015). Prueba de ello han sido el documento técnico elaborado por el ICANH (2017) y la Acción de tutela 1758 (2017) contra el Departamento Administrativo Nacional de Estadística (DANE) y el Ministerio del Interior interpuesta por diversas organizaciones campesinas nacionales y regionales, donde se pide incluir la categoría "campesino" dentro del Censo Nacional de Población y Vivienda; al mismo tiempo se argumenta que dicha categoría representa un grupo social diferenciado por sus dimensiones sociológico-territorial, sociocultural, económico-productiva y organizativo-política.

El campesinado se constituye históricamente. Su génesis y transformación están relacionados con el proceso de acumulación de capital de cada periodo histórico y las distintas formas de vida campesina asociadas a ellos. Por tanto, los campesinos son productos históricos específicos, lo que implica a su vez concebir sus orígenes comunitarios múltiples y diversos, así como sus trayectorias variables y diferenciadas. Es necesario concebir la configuración de comunidades campesinas en relación con las tendencias de la producción agropecuaria, los procesos políticos, el rol de la violencia y la presencia de múltiples actores en el campo (ICANH, 2017, p. 2)

La ACVC, como organización, ha movilizado la categoría de campesino en diversas acciones colectivas (ocupaciones, marchas, plantones), en la realización de proyectos de intervención social en las veredas de la región, en las negociaciones con el gobierno nacional y local y en diferentes escenarios de discusión de las problemáticas rurales. Además, reivindica la identidad campesina no solo para los agricultores familiares, sino que lo hace también para todos aquellos pobladores rurales que desarrollan las más diversas actividades en la región: cocaleros, pequeños mineros, mujeres rurales, líderes, pescadores, jornaleros, arrieros, aserradores y colonos, entre otros.

La movilización de la identidad campesina por parte de organizaciones sociales como la ACVC (u otras) se comprende al indagar sobre las posibilidades y satisfacciones que tal identidad ofrece a estos grupos como, por ejemplo, el acceso a la ciudadanía, es decir, la identidad (el nosotros) tiene funciones de protección y 
promoción política ante el Estado (Arias, Bolívar, Ruiz \& Vásquez, 2006). Al ser pobladores de áreas rurales con dificultades para la realización de actividades agrícolas y pecuarias por las precarias condiciones de infraestructura y acceso a los mercados, habitantes de una región con fuerte presencia de actividades ilegales como los cultivos de coca y la minería artesanal, además de una historia marcada por la presencia de guerrillas, "quieren ser campesinos y han decidido luchar por ello" (Bartra, 2008, p. 11), ${ }^{1}$ puesto que es una posibilidad real de vida e interlocución con el Estado y sus instituciones.

Para comprender esta reivindicación y movilización de la identidad campesina, se hace imprescindible discutir el término identidad, cuyas diversas acepciones, según Dubar (2006), podrían ser agrupadas en dos grandes corrientes: la esencialista y la nominalista. La primera corriente postula la existencia de una esencia que se mantiene inamovible a pesar de los cambios y del tiempo, como un nosotros (o un yo) que se mantiene igual, sin variaciones a lo largo de la historia; en esta perspectiva la identidad agrupa a aquellos que comparten una misma esencia inmutable y unívoca. Por su parte, la corriente nominalista plantea que la identidad es el resultado de una doble operación: diferenciación -aquello que hace singular y único a alguien o a alguna cosa con relación a otra diferente- y generalización - aquello compartido entre una clase de elementos que se diferencian de otra clase-; en esta perspectiva no hay identidad sin alteridad y tanto la una como la otra varían históricamente y están dadas por su contexto de definición. En esta perspectiva no existen pertenencias esenciales, por ello, no existen diferencias específicas a priori ni permanentes entre los individuos o grupos; en otras palabras, la identidad es producto de la historia y por lo tanto es construida. Para Dubar (2006) existen modos de identificación que varían a lo largo de la historia y del contexto, y pueden ser identificaciones atribuidas por los otros o reivindicadas por el individuo o grupo.

En esta perspectiva nominalista de la identidad, también denominada constructivista, se inscriben los planteamientos de Stuart Hall (2003) que entiende la identidad y los procesos de identificación como una construcción, como procesos siempre en desarrollo, profundamente anclados en procesos históricos, de cambio y transformación. Desde la perspectiva de Hall (2003) la(s) identidad(es) no son singulares ni unívocas, por el contrario, son estratégicas y posicionales; son construcciones a partir de prácticas, discursos y posiciones que incluso pueden llegar a ser contradictorias. La identidad es un concepto profundamente relacional, necesita de lo que está afuera para consolidarse, está sujeta al juego de la diferencia, del otro, es demarcación de la diferencia y solo puede constituirse a partir de la relación con aquello que no se es, con el otro, se construye dentro de la representación. En palabras de Hall (2003):
${ }^{1}$ Tomamos la expresión de Bartra (2008) al referirse al MST: "Por si quedara duda de que la condición campesina no se agota en un modo de producir y de convivir, una de las organizaciones latinoamericanas más representativas del campesinado como clase, el brasileño Movimiento de los Sin Tierra (MST), está compuesta principalmente por marginados urbanos $y$ rurales que quieren ser campesinos y ban decidido luchar por ello. No es por lo que son en términos económicos y sociales, sino por lo que han elegido ser, que los Sin Tierra marchan en la avanzada del movimiento campesino mundial" (p. 11).

\section{territarios 42-Especial}

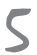




\section{territarias} 42-Especial
Uso «identidad» para referirme al punto de encuentro, el punto de sutura entre, por un lado, los discursos y prácticas que intentan «interpelarnos», hablarnos o ponernos en nuestro lugar como sujetos sociales de discursos particulares y, por otro, los procesos que producen subjetividades, que nos construyen como sujetos susceptibles de «decirse». De tal modo, las identidades son puntos de adhesión temporaria a las posiciones subjetivas que nos construyen las prácticas discursivas (p. 20).

En esta misma línea, Escobar (2015) —además de destacar el carácter histórico, procesual y relacional de la identidadseñala los compromisos éticos que esta implica, es decir, los participantes están interesados en la transformación de situaciones particulares y en ese proceso se da la "creación de espacios en los que nuevas maneras de saber, ser y hacer emergen como posibilidades históricas de situaciones problemáticas dadas" (p. 248).

En ese sentido, ante la necesidad de afrontar y dar respuesta a la actual crisis ambiental y a las precarias condiciones socioeconómicas que enfrenta la mayor parte de la población, están surgiendo y construyéndose nuevas identidades colectivas y formas de organización social, al tiempo que se cuestiona al Estado, su autoritarismo y la centralidad de su poder (Leff, 2004a, p. 396). La agenda ambiental de organizaciones como la ACVC evidencian, en concordancia con los planteamientos de Leff (2004a), que las demandas y las luchas de las organizaciones campesinas están transitando de un carácter reivindicativo meramente económico, hacia un movimiento político y económico más amplio por "la reapropiación de sus medios naturales de producción y de existencia" (p. 414).

En concordancia con esta línea de análisis, surge el interés por indagar cómo ha sido el proceso de construcción y movilización de la identidad campesina en el valle del río Cimitarra a través de la creación de iniciativas comunitarias de protección al medio ambiente. Para ello, se parte principalmente de los testimonios de los campesinos y campesinas que han estado ligados a la ACVC, intentando visibilizar elementos internos y externos que han marcado la trayectoria de esta organización, así como las transformaciones vividas en el territorio y los acuerdos construidos por las comunidades. El argumento central de este artículo es que la Línea Amarilla como iniciativa de protección del bosque ha permitido a la asociación $\mathrm{y}$ a sus miembros construir y movilizar la identidad campesina frente al Estado y sus instituciones, en la medida que se ha configurado como un actor colectivo, un "nosotros", que defiende y conoce el bosque y la biodiversidad de la región. Todo ello en un contexto de exigencia al Estado del reconocimiento del campesinado, su particular relación con la tierra y el territorio, sus formas organizativas, sus saberes, en últimas, su identidad.

Para responder esta pregunta se realizó un estudio cualitativo con perspectiva de 
memoria histórica. La memoria colectiva adquiere importancia en los procesos de construcción de identidad, por cuanto son procesos que se construyen mutuamente; así, la referencia a un pasado común permite fortalecer el sentido de pertenencia a un grupo o comunidad y crear procesos de valoración de sí mismo y del grupo. La memoria sobre momentos de violencia política abre el debate sobre la construcción de futuros democráticos en los que los derechos humanos se garanticen a toda la población, sin exclusión. De esta forma, hacer memoria es construir un pasado en función del futuro que se desea (Jelin, 2002).

Debe resaltarse que este artículo se inscribe en el proyecto de investigación Memoria histórica de la Asociación Campesina del Valle del río Cimitarra, cuyos ejes de análisis fueron (i) el proceso de colonización de la región y el surgimiento de la asociación, (ii) los hechos de violencia vivenciados en el marco del conflicto armado y las afectaciones que estos tuvieron sobre la organización comunitaria, (iii) las diversas estrategias implementadas por la ACVC para resistir a la guerra, (iv) las mujeres campesinas y el género, y (v) las potencialidades y expectativas de la asociación frente al proceso de paz entre las FARC y el Gobierno nacional. El trabajo de campo del proyecto de investigación se realizó a través de 18 visitas a los municipios y veredas de la zona ${ }^{2}$ entre mayo de 2017 y noviembre de 2018 , en las que se llevaron a cabo 40 entrevistas (a 15 mujeres y
25 hombres), 8 talleres de memoria ${ }^{3}$ y la participación del equipo de investigación (en calidad de observadores) en eventos propios de la organización campesina. ${ }^{4}$ Además, se realizó revisión documental de archivos de prensa y material de difusión de la ACVC. De ese modo, para la construcción de este artículo se hizo uso del material recopilado durante el proceso de investigación en mención, con énfasis en una de las iniciativas de resistencia implementada por la ACVC referente a la conservación y protección del medio ambiente: Línea Amarilla, y cómo su puesta en marcha desde la década de 1980 ha permitido a esta organización construir y movilizar la identidad campesina.

\section{La colonización: río abajo y río arriba}

El valle del río Cimitarra se ubica geográficamente sobre el costado oriental de la cordillera central, parte media del río Magdalena, y al sur de la serranía de San Lucas (figura 1). Por su ubicación, es una zona diversa tanto ecológica como socioculturalmente. Su poblamiento se originó a partir de migraciones espontáneas y vía fluvial provenientes de regiones con violencia política bipartidista y por expulsiones generadas por otros tipos de violencias desde mediados de siglo Xx (Prada, 2006, pp. 168-169). De hecho, muchos de los colonos provenían de la subregión sur del Magdalena Medio (Puerto Berrio, La Dorada, Puerto Parra,
${ }^{2}$ Las actividades del proyecto se realizaron en los cascos urbanos de los municipios de Yondó y Remedios, Antioquia; Cantagallo y San Pablo, Bolivar, y Barrancabermeja, Santander. Las veredas visitadas se ubican en estos mismos municipios: Puerto Matilde, Campo Bijao, La Poza, San Lorenzo, Cuatro Bocas, Carrizal y San Juan Alto.

${ }^{3}$ Se llevaron a cabo 5 talleres de la memoria en las seccionales de trabajo de la ACVC: nordeste antioqueño (2), sur de Bolivar (1) y seccional media (2). Un taller con los colonos fundadores de la asociación y dos con lideresas de la región.

${ }^{4}$ Eventos tales como reunión del Comité de Bufaleros de la ACVC, lanzamiento de la iniciativa Bosques de Paz en la vereda Puerto Matilde (Yondó), reunión de la Coordinadora de mujeres de la $A C V C$, talleres sobre reparación colectiva e identificación del daño realizados por la Defensoría del Pueblo a miembros de la organización y encuentro de mujeres de la ZRC.

\section{territorias 42-Especial}

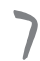




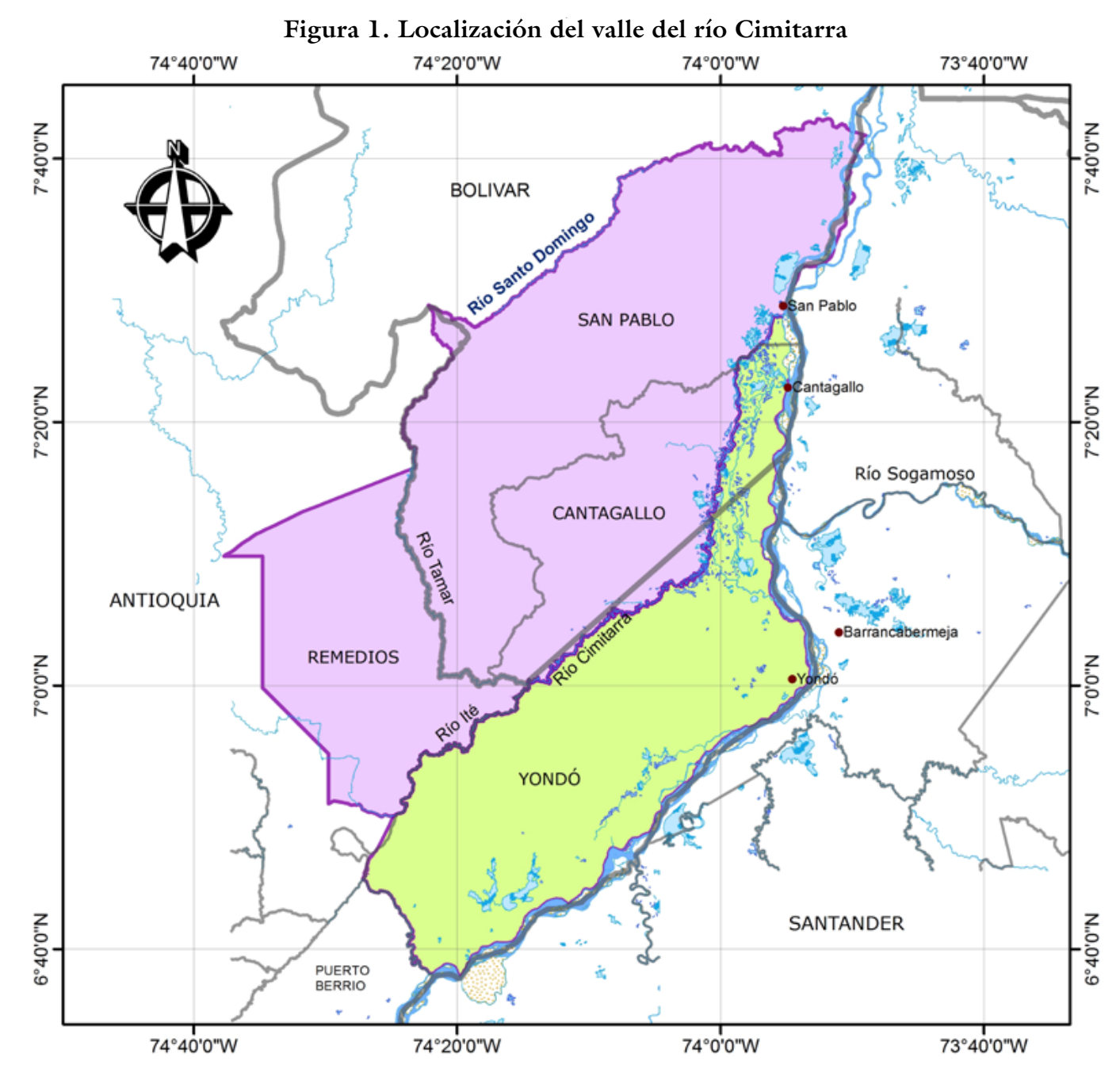

Fuente: PNUD y ACVC (2014).

Puerto Boyacá, Cimitarra, Puerto Nare), donde la violencia se intensificó en los años 80 ; entraron a la región por el río Cimitarra y luego por la quebrada San Francisco y fundaron las veredas La Concha, El Bagre, San Francisco y Jabonal (Murillo,
1994, p. 195). Igualmente, algunos mineros en busca de oro descendieron del municipio de Remedios y cruzaron hasta Yondó, Barrancabermeja y San Pablo. Así, convergieron poblaciones de distintas regiones del país que entraban y salían, 
quienes llevaron consigo sus tradiciones, prácticas culturales y productivas e historias de vida. En ese sentido, el valle es un lugar profundamente multicultural y con una gran biodiversidad.

En la memoria de los campesinos de la ACVC, ha quedado marcada la coexistencia de diversos actores, desde empresas petroleras, madereras, ganaderos y palmeros, hasta trabajadores dedicados a la actividad minera o migrantes temporales o definitivos relacionados con los cultivos de coca. Esto ha generado flujos de entrada y salida de gente, creación de circuitos comerciales y vías de acceso a la zona. Así, las tierras de colonización se convirtieron en foco de disputa por la tierra y relaciones en constante tensión. Uno de los campesinos retrata parte la dinámica de las empresas petroleras y la explotación de madera:

lo que yo quiero contarle es que en ese entonces [1970], había dificultades, no había vías, no entraba sino un ramal de carretera que había hecho la Shell-Cóndor, que fue la empresa que vino a explorar petróleo en lo que hoy es el territorio de Yondó (...) entonces esa disputa era como una disputa también territorial $(\ldots)$ pero cuando ya nosotros empezamos la creación del municipio de Yondó (1979) ahí ya los intereses eran por el hidrocarburo, entonces que de Ecopetrol empiezan a traer concesionarias, a seguir explorando petróleo, pero en la colonización estábamos por el interés de las maderas y el aporte que hacíamos era la agricultura, con el arroz, pero entonces ahí ya empezó a trabajarse sobre la pequeña ganadería (Martínez, C., Entrevista, septiembre 15 de 2017).

Para ese entonces, algunos colonos llegaban río abajo o río arriba, otros por las carreteras y trochas construidas por las empresas petroleras o siguiendo a los mineros y aserradores o viceversa, los mineros y aserradores siguiendo a los colonos. Los aserradores compraban madera y, con ello, los colonos podían "hacer una finquita, o lo que llaman un fundo" (Téllez, J., Entrevista, noviembre de 2017). Con todo esto, quedan los trazos de una gran biodiversidad de flora, fauna y fuentes hídricas ${ }^{5} \mathrm{y}$, al mismo tiempo, una pérdida de esta, consecuencia de la utilización de los recursos naturales.

La figura 2 muestra que la deforestación en el valle del río Cimitarra se ha extendido desde el nororiente Antioqueño, foco histórico de los cultivos de uso ilícito y la extracción ilegal de minerales, que expande la frontera agropecuaria hacia los bosques remanentes de la Serranía de San Lucas.

\section{Colonización y acuerdos comunitarios}

Para los campesinos, la colonización en el valle del río Cimitarra fue la "semilla" que creció con los acumulados de experiencias anteriores y generó elementos políticos, económicos y sociales que se integraron
${ }^{5}$ Esta biodiversidad quedó demostrada en la caracterización biológica del área sur de la serranía de San Lucas impulsada por la ACVC en el año 2015, que abordaremos más adelante.

territarios 42-Especial 
Figura 2. Cambio de cobertura boscosa en el valle del río Cimitarra entre 1990 y 2016

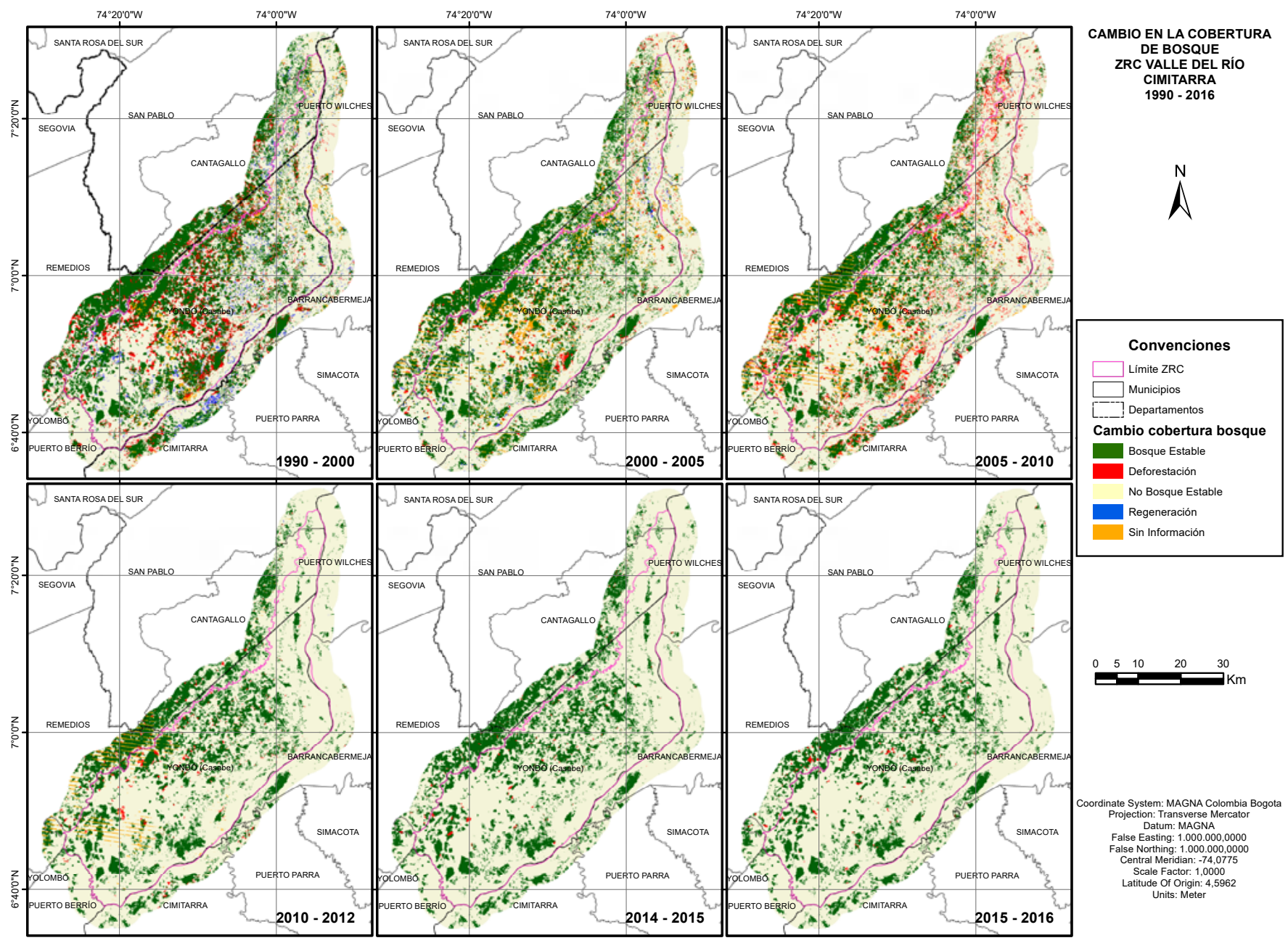

Fuente: FAO \& ANT (2018)

en la construcción de un nuevo territorio. Antes de ser desplazados, a finales de la década de 1970, los colonos que vivían en las inmediaciones de Ciénaga Barbacoas, municipio de Yondó, límites con Puerto Berrío, recuerdan que el proceso de colonización que estaban viviendo en ese lugar fue acorde con las necesidades del campesino, es decir, fácil acceso a recursos naturales: buena tierra, caza y pesca. Fue una colonización que se guiaba por el "ánimo de tener un patrimonio en el ámbito 
del núcleo familiar, con la solidaridad y la hospitalidad del campesino", pero con la particularidad de no contar con la suficiente organización para resistir, como recuerda uno de los campesinos a modo de aprendizaje: "creo que esa parte de no haber tenido concebido un contexto económico y político de la defensa del territorio nos jodió y nos puso a reflexionar (...) perdimos y aprendimos" (Martínez, C., Entrevista, septiembre 15 de 2017).

Perdieron porque tuvieron que desplazarse nuevamente y aprendieron porque producto de ello los campesinos comprendieron la importancia de la organización comunitaria para lograr la permanencia en el territorio. De acuerdo con campesinos fundadores de la ACVC, que vivieron en esta zona del municipio de Yondó en las décadas de 1970 y 1980 , el proceso de colonización había llegado allí a mediados de los años setenta proveniente de municipios como La Dorada, Yacopí y Puerto Berrío, compuesto por campesinos desplazados de anteriores zonas de colonización. El proceso en la época consistía en tomar la tierra y distribuirla en fincas no mayores a 200 hectáreas por familia, ${ }^{6}$ que era regulado por la organización comunitaria existente en la época: el Comité de Tierras. Ya instalada la colonización, el comercio de los productos agrícolas, así como el acceso a bienes y servicio, se hacía con Puerto Berrío y Yondó. Posteriormente, en la década de 1980, inició la presión hacia el campesinado por parte de grupos paramilitares instalados en Puerto Berrío, que impidió la libre movilidad entre la zona de colonización y el casco urbano, mediante amenazas a líderes comunitarios y retenes en los que se impedía el ingreso de víveres y medicamentos, al tiempo que se ejercía control sobre quienes entraban y salían de la zona. Luego, entre 1983 y 1992 fueron las masacres y las incursiones paramilitares a los caseríos. ${ }^{7}$ Este contexto de violencia armada fue el que enmarcó la compra de tierras por parte de aquellos que aprovecharon el temor de los campesinos y la presión paramilitar para comprar a bajo costo las propiedades (G. Guerra, entrevista, 9 de febrero de 2017).

Esta situación de violencia expulsó a los campesinos hacia las estribaciones de la zona sur de la serranía San Lucas al encuentro con los otros frentes de colonización espontánea que se habían adentrado a la zona por el río Cimitarra. El empuje de la colonización permitió que los colonos encontraran intereses y desafíos comunes ante las contradicciones que se venían presentado. A diferencia de las experiencias anteriores, esta forma de combinar la "solidaridad" tenía un "criterio", es decir, un objetivo común que trascendía el bienestar de la familia y el patrimonio y se dirigía hacia la lucha por el territorio. El final de la década de 1980 marca una nueva fase en ese sentido, a nivel local se fortaleció el espació de los comités de tierra, las Juntas de Acción Comunal y la creación de una cooperativa, desde donde se definían acuerdos y se hacían
- Para la época los terrenos ocupados por los colonos hacian parte de la Zona Reserva Forestal (ZRF) del Magdalena (Ley 2 de 1959). Sin embargo, después del paro cívico desarrollado en Barrancabermeja en 1975, en el que participaron campesinos de la región, el gobierno nacional - como parte de los acuerdos con el comité cívico que lideraba el paro-sustrajo de la ZRF los terrenos de Yondó-Casabe mediante el Acuerdo 02 de 1976 del Inderena. Según la misma resolución, estas tierras serian destinadas a procesos de titulación para los campesinos colonos de la zona.

${ }^{7}$ Los hechos violentos identificados que propiciaron el abandono de tierras por parte de los campesinos y la compra por parte de terceros son los siguientes:

- En el mes de octubre de 1983, en la vereda Barbacoas, hombres armados identificados como paramilitares ingresan por el rio, se instalan en la zona, amenazan a los campesinos para que se vayan, roban enseres, animales $y$ viperes $y$ posteriormente queman el caserio (G. Guerra, entrevista, 9 de febrero de 2017).

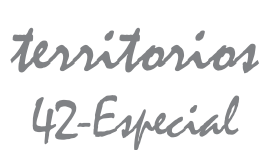


Además, por aquella misma época se da el asesinato de líderes campesinos en las veredas San Francisco y Puerto Nuevo Ité.

- Entre 1986 y 1991, el asesinato de 12 líderes pertenecientes a la Unión Patriótica (UP) en diversas zonas del área rural y urbana del municipio de rondó. Entre los casos debe destacarse el asesinato de concejales electos por la UP en el municipio y de lideres campesinos militantes del mismo partido (Romero, 2011).

- En 1989, paramilitares ingresan a la vereda Barbacoas, torturan y asesinan a dos campesinos de la región. Lo que genera desplazamiento y el abandono de varias fincas de la zona (Nunca Más, 2001).

- Los campesinos de la zona también recuerdan la masacre en la vereda La Congoja por parte de paramilitares en el año 1992 (G. Guerra, entrevista, 9 de febrero de 2017).

${ }^{8}$ Los campesinos entienden por recolonizar el volver a iniciar un proceso de colonización después de haber vivido un proceso de colonización anterior y haber sido expulsados de esas tierras.

\section{territarias 42-Especial}

esfuerzos para la "distribución cualitativa de la tierra", la comercialización y el suministro de alimentos. Se compartieron alimentos, semillas, herramientas y pies de cría de animales domésticos (gallinas, cerdos, patos), así como el trabajo para levantar los primeros ranchos de madera y palma. En palabras de los colonos:

todo eso era casi que un compromiso de los colonos que ya existíamos con el colono que llegaba y el que llegaba ya al año tenía esa garantía, entonces se comprometían también $(. .$.$) esa solidaridad surgió en la$ recolonización ${ }^{8}$ por la necesidad de la distancia, la soledad, la falta de los productos, la falta del dinero para comprar los productos.

\section{Gilberto insiste en que:}

El primer año usted recibía de los campesinos que ya estaban en la frontera que iba la colonización [el punto de avance del frente de colonización], yuca, plátano, pie de cría en aves, en cerdos (...) y luego, semillas de ese mismo producto para que usted sembrara donde estaba, la solidaridad que se merecía el compañero que llegaba, el espíritu de la solidaridad es uno de los tantos temas del criterio y al año, en la asamblea siguiente usted ya con un año de convivir con esta colonización tenía derecho a decidir si se quedaba o se iba, si en ese año decidía que me quedo estaba totalmente comprometido con el criterio y ya el criterio tenía el término, decir que un objetivo en común para la región era que yo no solo iba a trabajar por el bienestar de mi familia y mi patrimonio, sino iba a comprometerme con la lucha por el territorio y la defensa del mismo, ese es el criterio, independiente de, mejor dicho, de la forma de pensar de la persona, ahí no tenía que ver, yo podía venir desplazado, podía haber sido liberal, conservador, bueno casos sucedieron (Guerra, G. Entrevista, 21 de marzo de 2015).

Después de 1982, las relaciones entre los colonos fueron asumiendo como "criterio" que el proceso colonizador fortaleciera la permanencia y construcción de un territorio campesino. Muchos de los que habían llegado a la zona habían pasado por el ciclo "migración-colonización-conflicto-migración", ${ }^{9}$ dejando atrás tierras, familia, amigos, trabajo y proyectos. Ante esta experiencia, se dieron nuevas relaciones, actividades y un proceso organizativo que buscó transformar la realidad y la construcción de un orden deseado. La capacidad de los campesinos residió en mantenerse con lo básico, es decir, colonizar y "producir para el consumo familiar y el de sus animales domésticos", y, a su vez, construir una expectativa colectiva frente a la colonización.

En ese momento surgen las primeras estrategias organizativas:

1) La vereda Puerto Nuevo Ité y la cooperativa (Cooperativa de Pequeños y Medianos Agricultores, Copemantioquia), allí instalada, se convirtieron en un referente político, económico y 
organizativo. En torno a la cooperativa se fortaleció un grupo importante de líderes, algunos militantes del Partido Comunista ${ }^{10}$ y otros que venían desplazados por la violencia, quienes en asambleas de socios de base fueron construyendo los propósitos de las zonas de colonización. Como parte de esta estrategia organizativa, la cooperativa buscó económicamente atender el problema de los intermediarios, la comercialización de madera, oro y el suministro de alimentos, medicinas e insumos.

2) Los comités de tierra, en algunos casos, surgieron antes que las Juntas de Acción Comunal, su importancia, según los propios colonos, fue facilitar la creación de acuerdos comunitarios sobre alinderamiento de las tierras colonizadas, tamaño de los terrenos para las familias, reglas para el aprovechamiento de los recursos naturales (agua y madera) y ubicación de tierras baldías disponibles. Los comités jugaron un papel fundamental en la distribución de tierras para los colonos en las zonas rurales de los municipios de Yondó, Remedios, Cantagallo, la parte media del nordeste de Antioquia y en menor proporción en San Pablo, entre 1988 y 1993.

3 ) En cuanto a las Juntas de Acción Comunal, su historia desde los años 60 está presente en los colonos. Su doble carácter de asociación comunitaria e institucional facilitó la reconstitución de las comunidades y la posibilidad de una relación más directa entre las demandas específicas del territorio y las administraciones públicas. Fue a través de sus líderes que se creaban redes de vínculos sociales y políticos con los que se canalizaban ayudas y se negociaba para trabajar en las veredas. Las juntas son consideradas como una "herramienta", un derecho y "una representación legal” para gestionar proyectos y "recursos para el beneficio social de las comunidades". En la práctica, las Juntas de Acción Comunal, ante las condiciones en el territorio y la ausencia estatal, potencializaron colectivamente una serie de tareas y acuerdos, es decir:

Primero que todo, el abandono estatal, aquí había, y hay que decirlo, todavía hasta hace poco seguía habiendo presencia del Estado, pero en lo que tenía que ver en la parte bélica de conflicto y de guerra, entonces esta región cuando nosotros llegamos no había profesores, no había escuelas, no había carreteras, no había puestos de salud, no había nada. Desde las juntas de acciones comunales pagábamos los profesores, desde las juntas de acciones comunales montábamos un botiquín, desde las juntas de acciones comunales construíamos una escuelita para que los niños estudiaran y en ese orden y desde las juntas de acciones comunales le hacíamos mantenimientos a los
9 Este ciclo es identificado por Fajardo (1996) como una peculiaridad del proceso de colonización en Colombia que reproduce las estructuras agrarias $y$ sus contradicciones en la frontera agrícola.

${ }^{10}$ Algunos lideres campesinos militaban en el Partido Comunista en sus zonas de origen, tras el desplazamiento y durante el proceso de colonización su experiencia organizativa previa fue fundamental para la organización campesina.

\section{territarias 42-Especial}


${ }^{11}$ De acuerdo con los relatos campesinos y con diversas fuentes secundarias (Nunca Más, 2001; Becerra, 2005), en el marco de un operativo militar y tras una serie de bombardeos, la Cooperativa de Pequeñosy Medianos Agricultores fue incinerada y saqueada en 1989 por parte del Ejército. Años después, en 1996, sería nuevamente incinerada tras una incursión paramilitar.

${ }_{12}$ Algunos lideres campesinos se vincularon a la Unión Patriótica, partido politico surgido de los diálogos de paz entre el gobierno Betancur y la guerrilla de las FARC. Incluso en la década de 1990 el movimiento campesino logró representación en el Concejo Municipal del municipio de Yondó a través de candidatos pertenecientes a este partido político.

${ }^{13}$ Este municipio en el departamento de Santander es considerado la capital de la región de Magdalena Medio, con una población aproximada de 200000 babitantes. Los campesinos de la región llevan al casco urbano de este municipio sus productos $y$ diversas instituciones instalan en esta ciudad sus sedes para atender a la población de los municipios vecinos.

\section{territarias 42-Especial}

caminos para transitar la gente y caminos de herradura y el mantenimiento al río como medio de transporte que era el único que teniamos (Manzano, A. Entrevista, 25 de febrero de 2018).

\section{4) Los acuerdos comunitarios y la Línea} Amarilla. La organización campesina había logrado acuerdos comunitarios para la conservación de la fauna y flora de la zona: tiempos de veda para la pesca, la prohibición de la caza indiscriminada y la conservación de los bosques en las nacientes de agua; estos acuerdos fueron la base para el establecimiento de lo que hoy se conoce como Línea Amarilla. Tras la quema de la Cooperativa ${ }^{11}$ los campesinos decidieron en asamblea comunitaria, aproximadamente en 1989, ponerle un freno a la colonización y generar alternativas para la seguridad de sus vidas. Se decidió entonces, con el consenso tanto de las organizaciones comunitarias - JAC, comités - como con el de actores armados presentes en la región -ELN y FARC-EP-, delimitar un área de selva en la hoy conocida Serranía de San Lucas, que aún se conservaba sin intervención, y prohibir dentro de ella cualquier actividad productiva o extractiva (Narváez, 2018). Esa delimitación se hizo a través de la marca de los árboles del "borde" del área con una línea amarilla. Algunos pobladores relatan que el color amarillo fue elegido en honor a la Unión Patriótica, ${ }^{12}$ pues al unirse la marca amarilla con el verde de la selva quedaban representados los colores de la bandera de este partido político. De ahí que a esta área la conozcan como Línea Amarilla, aunque muchos pobladores también la conocen como El baldío o Zona baldía.

\section{6: Nace la asociación}

La creación de la ACVC se dio entre 1996 y 1998, en medio de dos grandes movilizaciones de carácter regional: la Marcha de los Parques (1996) y el Éxodo Campesino (1998). En ambas, juntas de acción comunal rurales y urbanas, comunidades campesinas, mineras, pescadoras y cocaleras de los municipios de Yondó, Remedios (Antioquia), San Pablo y Cantagallo (Sur de Bolívar) marcharon hacia Barrancabermeja. ${ }^{13}$ Esta gama de actores sociales a nivel local y regional buscaba soluciones y el cumplimiento de acuerdos que ya habían sido firmados con el gobierno nacional y formular nuevas demandas respecto a los derechos humanos, las políticas agrarias, mejores condiciones de vida y el avance del paramilitarismo sobre la región.

Sin embargo, la ACVC también es el resultado del proceso de colonización del valle del río Cimitarra. Con ello, emergieron liderazgos y estrategias para apropiarse del territorio, valorar los ecosistemas y, consecuentemente, redefinir 
la relación de los pobladores con los recursos disponibles. Es una comunidad, según Barreto (2017), que ha formado de manera endógena una forma de gobierno de los recursos de uso común. En otras palabras, la ACVC es una organización que ha construido un marco normativo, condiciones de autogobierno y lógicas de acción colectiva que "propenden [por] la ética ambiental en el uso y apropiación del territorio" (Barreto, 2017, p. 8). Es una caso emblemático y descriptible en políticas públicas endógenas, que según Barreto (2017) son

el resultado de acuerdos colectivos en los cuales se definen objetivos, instrumentos y metas, que en su conjunto buscan orientar el comportamiento de los actores para que estos cooperen en un marco institucional de reglas de juego para solucionar o llevar a niveles manejables, situaciones consideradas como socialmente problemáticas (p. 4).

Lo que se quiere destacar en este caso es cómo el proceso de la organización campesina está inmerso en el sistema de recursos naturales del valle y al mismo tiempo cómo los ha gestionado frente al riesgo de deterioro constante por cuenta del conflicto armado, la minería ilegal, los cultivos ilícitos, la explotación de hidrocarburos, la deforestación, la expansión de la ganadería extensiva, los monocultivos de palma de aceite y el no reconocimiento de la misma organización campesina.

\section{Zona de Reserva Campesina y acuerdos comunitarios}

Con la creación de la ACVC en 1996, los acuerdos comunitarios se mantienen y fortalecen como parte de los propósitos e identidad de la asociación. Desde allí, se lideró la creación de la Zona de Reserva Campesina (ZRC) en 2002, ${ }^{14}$ como figura para defender el territorio de los intereses de los actores armados, multinacionales, narcotraficantes y ganaderos, como lo explicó un campesino de la asociación:

la última herramienta que nosotros tenemos en las manos como campesinos, es la Zona de Reserva Campesina, porque ni siquiera los campesinos colombianos tenemos derecho a la tierra. ¿Quién es el que tiene derecho a la tierra? El que tiene con qué comprarla, usted se puede comprar toda esta región y es uno solo y es el dueño de la tierra y es el que manda porque la compró, pero en el caso de nosotros que somos colonos, nosotros somos vulnerables a que nos saquen de la tierra. ¿Quién nos saca? Nos sacan los grupos armados o nos pueden sacar los cultivos de palma africana ${ }^{15}$ o la ganadería a través de sus métodos que tienen para sacar a los campesinos, bueno, todos auspiciados por el Estado. Y estamos acá y encontramos esta figura de Zona de Reserva Campesina, pues esa es la que nos ata más al territorio (Manzano, A. Entrevista, 25 de febrero de 2018 ).
14 La ZRC del Valle del Cimitarra fue creada mediante la Resolución 028 de 2002 del Incoder.

${ }^{15}$ Si bien en los municipios en los que se encuentra la ZRC (Yondó, Cantagallo, San Pablo y Remedios) los cultivos de palma de aceite solo iniciaron hacia el año 2004, en municipios vecinos como Puerto Wilches (Santander) el monocultivo de palma según Delgado (2006, p. 104) se remontan a la década de 1950.

\section{territorias 42-Especial}


${ }^{16}$ El Incora fue disuelto en 2003 dando lugar al Instituto Colombiano de Desarrollo Rural (Incoder), entidad que también fue liquidada en 2015 para dar paso a dos nuevas entidades: la Agencia Nacional de Tierras (ANT) y la Agencia de Desarrollo Rural (ADR).

17 "La Consulta Previa es el derecho fundamental que tienen los pueblos indigenas y los demás grupos étnicos cuando se toman medidas (legislativas y administrativas) o cuando se vayan a realizar proyectos, obras 0 actividades dentro de sus territorios, buscando de esta manera proteger su integridad cultural, social y económica y garantizar el derecho a la participación" (Rodriguez, 2010).

\section{territorias 42-Especial}

Las organizaciones campesinas en $\mathrm{Co}-$ lombia, después de diversos procesos de movilización, lograron la creación de la figura ZRC con la Ley 160 de 1994, que fue reglamentada posteriormente mediante el Decreto 1777 de 1996, cuyos procedimientos de selección y delimitación se establecen en el Acuerdo 024 de 1996 del antiguo Instituto Colombiano de Reforma Agraria (Incora). ${ }^{16}$ A pesar del avance que esta figura territorial significó, aún es insuficiente, pues no establece mecanismos de protección como la consulta previa, ${ }^{17}$ garantizada para los grupos indígenas y afrodescendientes en la legislación colombiana desde la Constitución de 1991. Es decir, a pesar de la existencia legal de la ZRC, existe una asimetría en la protección y reconocimiento de las comunidades campesinas — como señala Hernández (2015) - en comparación con los sujetos étnicos negros e indígenas, porque aunque los campesinos sean pobladores rurales con sus particularidades, con fuerte arraigo a la tierra y al territorio, con un sistema de organización y características culturales propias, no son reconocidos por el Estado como un sujeto de especial protección.

En otras palabras, las políticas multiculturalistas incorporadas a partir de la Constitución de 1991, al reconocer derechos desde la perspectiva étnica, dejaron a los campesinos sin herramientas para defender sus bienes materiales (recursos naturales) e inmateriales (formas de organización social) a pesar de ser importantes actores del mundo rural y compartir los territorios y sus problemas con las comunidades negras y los grupos indígenas (Hoffmann, 2016). Por ello, el reconocimiento político es una de las banderas de las movilizaciones actuales de la ACVC y demás organizaciones campesinas en Colombia. Incluye representación política, consulta previa y autoridad propia, así como el reconocimiento de su particular relación con la tierra y los recursos naturales. La exigencia por reconocimiento político se relaciona con la noción de identidad campesina en construcción dentro del propio movimiento, en un intento de superar y no limitarse a las nociones de etnicidad que han marcado el reconocimiento de comunidades negras e indígenas y excluido a los campesinos (Montenegro, 2016).

Esa búsqueda por el reconocimiento político emprendida por la ACVC considera la heterogeneidad propia del campesino de la región, que hace imposible hablar de una identidad monolítica y cohesionada, sin cambios en el tiempo y el espacio. Además, ese carácter diverso del campesino es consubstancial y tiene dos orígenes: primero, las diversas maneras de relacionarse con la naturaleza, que originan a diversos tipos tecnológicos, productivos, sociales y simbólicos, y segundo, las variadas formas como los campesinos se insertan al sistema mayor, que resultan en una diversidad socioeconómica extrema que va desde el autoconsumo a la agricultura comercial (Bartra, 2008).

Por ello, hablar de la ZRC como figura territorial implica reconocer que esta 
no se limita a lo legal y que aún es una figura en construcción, cuya definición "depende de la capacidad de los actores presentes, sean individuos, movimientos sociales o instituciones de gobierno, de pugnar por dispositivos adaptados a sus intereses y a los contextos" (Hoffmann, 2016 , p. 28). Para el caso, la ZRC como una figura territorial que permite el reconocimiento del campesino, su territorio y las formas como lo ha organizado a través de acuerdos comunitarios es tan importante para la conservación del bosque como la Línea Amarilla.

\section{La Línea Amarilla: experiencia comunitaria de protección del bosque}

Cuando empezamos allí, que hicimos la Línea Amarilla, eso hay que tenerlo en cuenta, porque nosotros no manejábamos cuando eso lo que era el medio ambiente, no manejábamos eso, entonces allí dijimos que había que hacer esa Línea Amarilla porque no podíamos tumbar más monte así fuera el rey o el mismo gobierno, que eso era del Estado pero no lo dejamos tumbar de nadie y por eso las juntas cuidan eso desde allí (Líder ACVC, Taller de la memoria con Fundadores de la ACVC, 29 de octubre de 2017).

La Línea Amarilla (figura 3 ) es el resultado de un proceso de colonización campesina con un fuerte componente organizativo. Cuando llegaron los primeros campesinos desplazados de otras regiones, estos construyeron una estrategia para ponerle un límite a la colonización, es decir, la delimitación de una zona de conservación en un contexto de expansión de economías extractivas centradas en la explotación maderera y caza. Fue un acuerdo para proteger aproximadamente entre 60000 y 70000 hectáreas de selva virgen en el área sur de la serranía de San Lucas.

Desde estos acuerdos se abre la posibilidad para la protección del bosque y fuentes de agua, humedales, especies de flora y fauna silvestre. También se regula vedas de pesca y cacería y los cultivos en los bordes de los ríos, entre otros. Su objetivo principal es la protección de la biodiversidad de la zona, la defensa del territorio y le apuesta a una economía campesina sostenible que garantice condiciones de vida digna (figura 3 ).

La persistencia del conflicto generó fuertes presiones sobre la Línea Amarilla, especialmente en el momento de la suspensión de la ZRC entre 2003 y $2010 .^{18}$ Adicionalmente, la expansión de la ganadería, los cultivos de coca como alternativa de ingresos, los impactos de la erradicación forzada y las fumigaciones con glifosato, ${ }^{19}$ la explotación de maderas, la expansión de la minería de oro, la solicitud de títulos mineros dentro del área de protección comunitaria y las condiciones de pobreza amenazan constantemente la autonomía, los acuerdos y la gestión de la organización campesina. Ante ello, la ACVC ratificó los
${ }^{18} \mathrm{La}$ ZRC del Valle del Cimitarra después de creada en 2002 fue suspendida por el Gobierno Nacional entre 2003 y 2010. La suspensión solo fue levantada en febrero de 2011 por el Incoder, que se encuentra vigente en la actualidad.

19 Las erradicaciones forzadas y las fumigaciones con glifosato que se hicieron hasta el 2015 sobre las plantaciones de coca en la región, se han traducido en mayor presión sobre la Línea Amarilla y el bosque que pretende conservar, pues los cultivadores de coca se adentran en el baldio para reactivar sus cultivos.

\section{territarias 42-Especial}

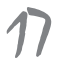


${ }^{20}$ Hilfswerk der evangelischen Kirchen Schweiz -HEKS, Wildlife Consevation Society - WCS, Laboratorio de la Universidad de Brescia, Italia -CETAMB, Programa de las Naciones Unidas para el Desarrollo - PNUD, Ministerio Federal del Medio Ambiente, Protección de la Naturaleza de Alemania

territarios 42-Especial

Figura 3. Ubicación de Línea Amarilla en los alrededores de la ZRC del valle del río Cimitarra

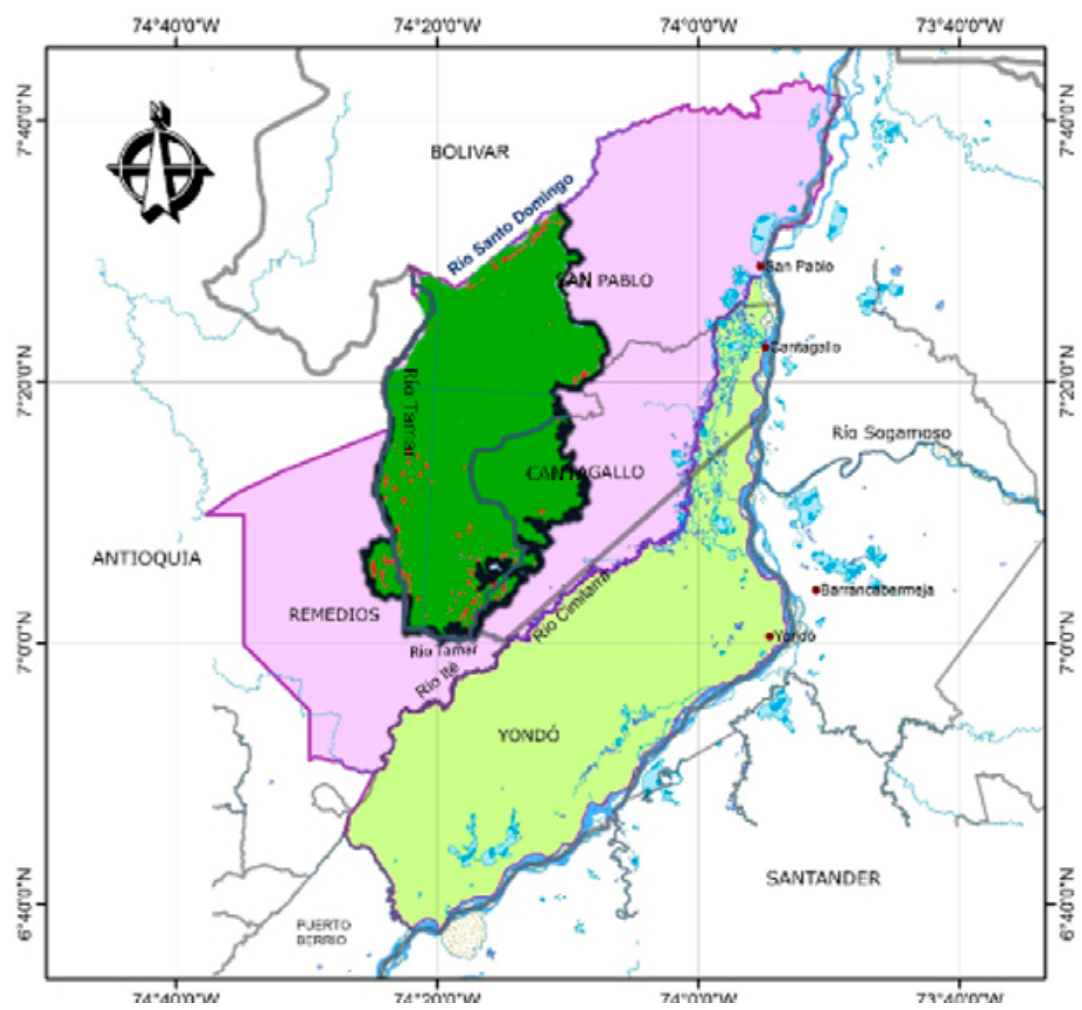

Fuente: PNUD y ACVC (2014).

acuerdos para la conservación de la Línea Amarilla, cuando, en el año 2001, adelantó una nueva jornada de "repintada" de los árboles del borde y asumió públicamente su papel protagónico en la protección de este bosque. "La formulación de la Línea Amarilla y la declaración de lleno en el 2001 cuando se hace de nuevo la repintada y se responsabiliza la asociación como protectora de ese territorio, sobre la Línea Amarilla" (Líder comunitario, Taller de la memoria seccional media ACVC, 15 de septiembre de 2017).

Además, la ACVC ha organizado campamentos ecológicos como espacios de educación ambiental e interacción con organismos de cooperación internacio$\mathrm{nal}^{20} \mathrm{y}$ autoridades ambientales tales como Parques Nacionales Naturales (PNN); también ha impulsado la creación de Comités Ambientales de las JAC, escenarios que traducen los acuerdos en normas ambientales y establecen sanciones en casos 
de incumplimiento (ACVC, CDPMM \& Incoder, 2012).

Debe destacarse que en 2015 la ACVC adelantó la caracterización biológica de las especies presentes en la zona protegida, con el apoyo técnico de diversas universidades, ${ }^{21}$ PNN de Colombia, Fundación Panthera, Proyecto Primates, Sociedad para la Conservación de la Vida Silvestre (WCS) y juntas de acción comunal, entre otros. Entre los hallazgos se destacan: 300 especies de mariposas; 32 especies de pequeños mamíferos; 29 especies de anfibios; 47 especies de reptiles; 5 especies de primates, todos en riesgo de extinción; 330 morfoespecies vegetales; 1708 especies de macroinvertebrados acuáticos; 263 especies de aves, entre ellas el pajuil y águila arpía, en riesgo de extinción; 45 especies de escarabajos coprófagos, y 11 especies de medianos y grandes mamíferos como antas, leoncillo, jaguar, tigrillo, jaguarundi y oso real o de anteojos, también en riesgo de extinción (Gómez, 2015). ${ }^{22}$

Así mismo, se han definido objetivos y estrategias de protección de humedales, las vedas de pesca, la regulación de la caza y la protección de hábitats de especies amenazadas como el manatí y el jaguar. Es de resaltar que la ACVC incluye en su Plan de Desarrollo Sostenible 2012-2022 la preservación y conservación de esta parte del territorio. Entre los avances logrados por la organización, se resalta la inclusión de la zona de la Línea Amarilla dentro del polígono de moratoria minera de la serranía de San Lucas (Resolución
1433 de 2017 , MADS) y el actual proceso de declaratoria como nueva área protegida para el país que ha venido impulsando la ACVC frente a PNN. ${ }^{23}$ Así, se traza un camino importante para que los acuerdos para la conservación se materialicen en figuras de protección comunitaria que puedan ser a su vez áreas protegidas reconocidas por las autoridades ambientales. Sin embargo, debe mencionarse que este proceso de declaratoria como área protegida por parte de PNN no está exento de dificultades y contradicciones debido a las restricciones que se establecen en las áreas de amortiguación de los PNN y las dificultades que ello acarrea para las comunidades campesinas que desarrollan sus actividades productivas en los límites del área.

\section{Reflexiones finales}

El trabajo presentado muestra cómo el proceso de la ACVC fue construyendo, desde el proceso de colonización, una manera diferente de pensar el territorio y la gestión de los recursos comunes frente a las lógicas de mercado y la violencia provenientes de dentro y fuera del territorio. A pesar de la biodiversidad que caracteriza la región, los recursos naturales (tierra, bosque, agua) sufren un progresivo acoso en la medida que se va interviniendo el área conservada a través de nuevos procesos de colonización impulsados por la minería de oro y la extracción de madera, principalmente, al tiempo que aumenta la entrada y salida de actores que no tienen
${ }^{21}$ Universidad Nacional de Colombia, Universidad de Antioquia, Universidad del Valle, Universidad de Caldas, Universidad de los Andes, Instituto Universitario de la Paz y Universitá degli Studi di Brescia (Italia).

${ }^{22}$ Las cifras de biodiversidad que PNN ofrece son diferentes debido a que se refieren a la totalidad de la Serrania, pero siguen evidenciando el potencial del área: "la Serranía de San Lucas se ubica un remanente de bosque continuo extenso, considerado el hábitat con mayor potencial para mantener poblaciones viables en el norte de Colombia. La biodiversidad registrada en la Serranía incluye 1093 especies de plantas, 71 géneros 0 morfotipos de macroinvertebrados acuáticos, 45 especies de escarabajos coprófagos, 185 de mariposas, 129 de peces, 69 de anfibios, 62 de reptiles, 587 de aves $y$ 191 de mamíferos" (PNNy WCS, 2015, citado por Parques Nacionales Naturales, 2019).

${ }^{23}$ La ACVC ha tenido acercamientos con la entidad en aras de lograr la declaratoria de la zona como área protegida. Como

\section{territarias 42-Especial}

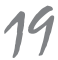


resultado de ello y de los estudios hechos por PNN, en la actualidad la serrania de San Lucas en su totalidad ha sido incluida en el portafolio de nuevas áreas protegidas (Parques Nacionales Naturales, 2019).

\section{territarias 42-Especial} 20 los mismos intereses ni comparten los acuerdos de las comunidades. A ello se suma la poca intervención del Estado en la solución de los conflictos y la falta de reconocimiento de la organización campesina y sus derechos.

El proceso de colonización del valle del río Cimitarra generó un fuerte sentido de identidad entre los campesinos colonos, quienes percibieron elementos comunes como historias de vida y desplazamiento, vecindad, intereses, tierras y recursos naturales. Desde allí, el entendimiento compartido y la complementariedad de acción permitió una forma de organización que buscó a través de la cooperativa, los comités de tierra, las JAC y, principalmente, la Línea Amarilla ponerle un límite a la colonización y explotación de los bienes comunes. La ZRC y los acuerdos que establecen las comunidades campesinas son una forma de ejercer el legítimo derecho a organizarse y a defender el territorio a partir de la visión territorial y participativa de las comunidades locales.

El caso de la ACVC y la puesta en marcha de la Línea Amarilla son también una invitación a "no congelar el concepto de campesino", a dejar de asumirlo como una categoría inmóvil, sin la capacidad ni el interés de adaptarse a nuevas circunstancias, al tiempo que logra mantener su visión de mundo y formas de organización social (Carneiro, 1998, p. 73). En esa dirección, la experiencia de la Línea Amarilla le ha permitido a la ACVC la construcción de una identidad campesina que no se limita a lo productivo (agrícola o pecuario). Por el contrario, posiciona a esta organización como un actor fundamental en la preservación del bosque y en un interlocutor necesario para el desarrollo de iniciativas institucionales de protección y conservación de la biodiversidad de la región.

En la actualidad, junto a los ecologistas, organizaciones ambientalistas y demás grupos que tienen por objetivo la preservación de la naturaleza, resurgen actores tradicionales del campo: campesinos, indígenas, afrodescendientes y pescadores que se posicionan como capaces de armonizar la producción y la conservación, a partir de la implementación de sus prácticas ancestrales e iniciativas comunitarias de preservación como la aquí analizada. En concordancia con Brandemburg (2010), esos grupos son portadores de racionalidades que se oponen y son alternativas a la lógica del sistema capitalista, a la lógica instrumental que ha colonizado el campo; son grupos que combinan subjetividad y racionalidad y protagonizan la reconstrucción del mundo rural.

Esos movimientos y sus estrategias se contraponen a la dominación exclusiva de un rural moderno sujeto a la lógica del mercado, contestan a la colonización de lo rural resignificándolo. Así, iniciativas comunitarias de protección del medio ambiente - como la Línea Amarilla - son una forma de consolidar una racionalidad ambiental (Leff, 2009; 2004a; 2004b) alternativa a la racionalidad económica imperante hoy, demuestran la necesidad 
que el Estado y la sociedad en general las reconozca en la tentativa de cambiar la dirección de la actual crisis ambiental y la creciente pobreza que afecta a gran parte de la población.

La Línea Amarilla, como las demás iniciativas comunitarias de protección del medio ambiente, evidencia la necesidad urgente y el pedido de las organizaciones campesinas por la ampliación de la democracia, que incluya la gestión colectiva de la naturaleza y sus recursos. Adicionalmente, estas experiencias colectivas generan elementos para la construcción de la identidad campesina, pues produce un nosotros: los campesinos que protegen el bosque, frente a otros que lo reducen a un expendio de recursos como el oro, el petróleo, la madera, que puede ser también el Estado y sus instituciones, en tanto es con quien se dialoga (a través de sus funcionarios) para lograr que la iniciativa campesina tenga respaldo y sea reconocida por las autoridades competentes.

\section{Referencias}

ACVC, CDPMM, \& INCODER. (2012). Plan de Desarrollo Sostenible de la Zona de Reserva Campesina del Valle del río Cimitarra - "Una iniciativa agraria de paz”. Barrancabermeja.

ACVC. (27 de mayo de 2017). A defender la zona de "Línea Amarilla" al sur de la serrania de San Lucas - Colombia. Recuperado de https://www.prensarural.org/spip/spip.php?article21569
Barreto, J. (2017). Políticas públicas endógenas ambientales y gobierno de los bienes comunes en la zona de reserva campesina del valle del río Cimitarra. Nuevo Derecho, 13(21), 177-196.

Bartra, A. (2008). Campesindios. Aproximaciones a los campesinos de un continente colonizado. Boletín de Antropología Americana (44), 5-24.

Becerra, S. J. (2005). Convicción, esperanza $y$ trabajo. la experiencia de una comunidad en resistencia: El caso de la Asociación Campesina del valle del río Cimitarra (ACVC). Bogotá: Universidad Nacional de Colombia.

Bolívar, I.(2006). Identidades culturales y formación del Estado en Colombia: colonización, naturaleza y cultura. Bogotá: Universidad de los Andes, Facultad de Ciencias Sociales, Departamento de Ciencia Política, CESO, Ediciones Uniandes.

Brandemburg, A. (2010). A colonização do mundo rural e a emergência de novos atores. RURIS - Revista do Centro de Estudos Rurais, 4(1). Recuperado de https://www.ifch.unicamp.br/ojs/ index.php/ruris/article/view/710

Carneiro, M. J. (1998). Ruralidades, novas identidades em construção. Estudos Sociedade e Agricultura, 6(2), 53-75. Delgado, Á. (2006). El conflicto laboral en el Magdalena Medio. En CINEP (Ed.), Conflictos, poderes e identidades en el Magdalena Medio 1990-2001 (pp. 85164). Bogotá: Colciencias - CINEP. territarias 42-Especial 


\section{territarias 42-Especial}

Dubar, C. (2006). A crise das identidades. A interpetação de uma mutação. Porto: Edições Afrontamento.

Escobar, A. (2015). Territorios de diferencia. Lugar, movimientos, vida, redes. Popayán: Universidad del Cauca.

Fajardo, D. (1996). Fronteras, colonizaciones, y construcción social del espacio. En C. Caillavet, \& X. Pachón (Ed.), Frontera y poblamiento: estudios de historia y antropología de Colombia $y$ Ecuador (pp. 237-282). Lima: Institut Français d'études Andines.

FAO \& ANT. (2018). Las Zonas de Reserva Campesina: retos y experiencias para su implementación en el marco de la Ley 160 de 1994. Contribución a la aplicación de las Directrices Voluntarias para la Gobernanza Responsable de la Tenencia de la Tierra, la Pesca y los Bosques en Colombia. Recuperado de http://www.fao.org/3/ca0467es/ CA0467ES.pdf

Gómez, F. (7 de Julio de 2015). Buscando mecanismos de protección de la selva virgen de la serrania de San Lucas. Recuperado de https://prensarural. org/spip/spip.php?article17387

Hall, S. (2003). Introducción: ¿quién necesita «identidad»? En S. Hall, \& P. du Gay (Eds.), Cuestiones de identidad cultural (pp. 13-39). Buenos Aires: Amorrortu Editores.

Hernandez C., M. J. (2015). Asimetrías en la protección de la forma de vida campesina colombiana. Hacia una protección especial de la forma de vida campesina. Revista Controversia, (205), 303-331. Hoffmann, O. (2016). Divergencias construidas, convergencias por construir. Identidad, territorio y gobierno en la ruralidad colombiana. Revista Colombiana de Antropologia, 52(1), 17-39. http:// doi.org/10.22380/2539472X1

ICANH. (Febrero de 2017). Elementos para la conceptualización de lo "campesino” en Colombia. Recuperado de https://www.dejusticia.org/ wp-content/uploads/2017/11/ Concepto-t\%C3\%A9cnico-del-Instituto-Colombiano-de-Antropo$\log \% \mathrm{C} 3 \%$ ADa-e-Historia-ICANH.pdf Jelin, E. (2002). Los trabajos de la memoria. Madrid: Siglo XXI Editores.

Leff, E. (2004a). Racionalidad ambiental. La reapropiación social de la naturaleza. México: Siglo XXI Editores.

Leff, E. (2004b). El movimiento ambiental por la reapropiación social de la naturaleza: seringueiros, zapatistas, afrodescendientes y pueblos indígenas de América Latina. En Autor, Racionalidad ambiental. La reapropiación social de la naturaleza (pp. 396-456). México: Siglo Xxi Editores.

Leff, E. (2009). Ecologia, capital e cultura: territorialização da racionalidades ambiental. Petrópolis: Vozes.

Matijasevic, M. T. (2015). Experiencias de reconocimiento y menosprecio en campesinas y campesinos de Caldas. Manizalez: Centro de Estudios Avanzados en 
Niñez y Juventud alianza de la Universidad de Manizales y el CINDE.

Montenegro, H. (2016). Ampliaciones y quiebres del reconocimiento político del campesinado colombiano: un análisis a la luz de la Cumbre Agraria, Campesina, Étnica y Popular (CACEP). Revista Colombiana de Antropología, 52(1), 169-195. https://www.doi. org/10.22380/2539472X7

Murillo, A. (1994). Yondó. En A. Murillo, M. T. Arcila, M. Alonso, G. Restrepo, \& G. Bonilla (Eds.), Un mundo que se mueve como el río. Historia regional del Magdalena Medio (pp. 171-206). Bogotá: Instituto Colombiano de Antropologia - Colcultura - PNR.

Narváez, S. (2018). Historia ambiental del valle del rio Cimitarra. "El problema es que la riqueza de esta región está en manos del campesinado, y quieren tenerla". Medellín: Universidad de Antioquia.

Nunca Más. (2001). Colombia Nunca Más. Crimenes de Lesa Humanidad. Zona XIV. Tomo I. Bogotá.

Ostrom, E. (2000). El gobierno de los bienes comunes. Evolución de las instituciones de acción colectiva. México: Fondo de Cultura Económica.

Parques Nacionales Naturales. (Julio de 2019). Portafolio de nuevas áreas y ampliaciones del ámbito de gestión nacional, liderado por Parques
Nacionales Naturales de Colombia. Recuperado de http://www.parquesnacionales.gov.co/portal/es/ sistema-nacional-de-areas-protegidas-sinap/ portafolio-de-nuevas-areas-protegidasdel-sistemas-de-parques-nacionales/ PNUD \& ACVC. (2014). Estudio participativo de tenencia de la tierra y el territorio, usos y conflictos en la ZRC del valle del río cimitarra. Barrancabermeja: PNUD - ACVC.

Prada, E. (2006). Las luchas campesinas en el Magdalena Medio 1990-2001. En CINEP/PPP (Ed.), Conflictos, poderes e identidades en el Magdalena Medio (pp. 165-242). Bogotá: CINEP.

Rodríguez, G. A. (2010). La consulta previa con pueblos indigenas y comunidades afrodescendientes en Colombia. Bogotá: Universidad del Rosario. Recuperado de https://www.urosario.edu.co/ urosario_files/lf/lfd9b49f-b7174dcl-8875-657612776cff.pdf

Romero, R. (2011). Unión Patriótica. Expediente contra el olvido. Bogotá: Centro de Memoria, Paz y Reconciliación, Alcaldía Mayor de Bogotá.

Silva Prada, D. (2012). Organización de la comunidad en medio del conflicto social y armado. El caso de la Asociación Campesina del Valle del río Cimitarra. Cuadernos de Desarrollo Rural, 9(68), 17-40. territarios 42-Especial 